\title{
Alcohol Dependence and Reproductive Onset: Findings in Two Australian Twin Cohorts
}

\author{
Mary Waldron, Andrew C. Heath, Kathleen K. Bucholz, Pamela A. F. Madden, \\ and Nicholas G. Martin
}

\begin{abstract}
Background: Although early alcohol use is a strong predictor of future alcohol problems and adolescent drinking is associated with risky sexual behavior predictive of early childbearing, reproductive dysfunctions associated with delayed childbearing have been reported in adult drinkers. We examine the relationship between lifetime history of alcohol dependence (AD) and timing of first childbirth across reproductive development.

Methods: Data were drawn from two cohorts of Australian twins born between 1893 and 1964 (3634 female and 1880 male twins) and between 1964 and 1971 (3381 female and 2748 male twins). Survival analyses were conducted using Cox proportional hazards regression models predicting age at first childbirth from $\mathrm{AD}$, with sociodemographic characteristics, regular smoking, history of psychopathology, and family and childhood risks included as control variables in adjusted models.

Results: Results suggest alcoholic women in both cohorts show overall delayed reproduction, with little effect of $\mathrm{AD}$ on timing of first reproduction in men. Effects of AD are particularly strong for women in the older cohort, where AD is associated with $73 \%$ decreased likelihood of first childbirth after age 29 [hazard ratio $(\mathrm{HR})=0.27,95 \% \mathrm{CI}: 0.10-0.75$ ]. In adjusted models, effects reduce only slightly $(\mathrm{HR}=0.29,95 \% \mathrm{CI}: 0.11-0.80)$. For women in the young cohort, $\mathrm{AD}$ is associated with delayed reproduction after age 24 , with $40 \%$ decreased likelihood of first childbirth $(\mathrm{HR}=0.60,95 \% \mathrm{CI}: 0.48-0.75)$. AD remains predictive in adjusted models, but without age interaction $(\mathrm{HR}=0.72,95 \% \mathrm{CI}: 0.62-0.85)$.

Conclusions: Findings of delayed reproductive onset in alcoholic women are consistent with alcohol-related reproductive dysfunctions, although underlying mechanisms remain largely unknown. To better understand $\mathrm{AD}$ differences in reproductive onset, continued research on both biological and psychosocial risks is needed.
\end{abstract}

Key Words: Alcohol Dependence, Reproductive Timing, Survival Analysis.

$\mathrm{T}$ EENAGE DRINKING IS a topic of much concern, with risky sexual behavior among the more immediate risks of personal harm (CASA, 1999). During adolescence, alcohol use and misuse is associated with early sexual onset (Bailey et al., 1999; Kinsman et al., 1998; Kowaleski-Jones and Mott, 1998; Lammers et al., 2000; Mott and Haurin, 1988; Small and Luster, 1994), greater frequency of sexual intercourse (Poulin and Graham, 2001), and history of multiple sexual partners (Bailey et al., 1999; Howard and Wang, 2004; Lowry et al., 1994; Santelli et al., 1998). In many studies (but not all, c.f., CASA, 1999), inconsistent or ineffective use

From the Midwest Alcoholism Research Center, Department of Psychiatry (MW, ACH, KKB, PAFM), Washington University School of Medicine, St. Louis, Missouri; and Genetic Epidemiology Unit, Queensland Institute of Medical Research (NGM), Brisbane, Australia.

Received for publication October 29, 2007; accepted June 12, 2008.

Reprint requests: Mary Waldron, PhD, Department of Psychiatry, Washington University School of Medicine, Campus Box 8134, 660 S. Euclid Avenue, St. Louis, MO 63110; Fax: 314-286-2213; E-mail: maryw@matlock.wustl.edu

This work was supported by NICHD Grant HD49024 and NIAAA Grants AA07728, AA11998, and AA15210.

Copyright (C) 2008 by the Research Society on Alcoholism.

DOI: 10.1111/j.1530-0277.2008.00771.x of contraception is also reported (Fergusson and Lynskey, 1996; Fortenberry et al., 1997; Hingson et al., 1990) and these behaviors together increase risk for sexually transmitted infection (STI), unplanned pregnancy, and early childbearing (Kirby, 2002; Manlove et al., 2000).

Among adults, excessive or problem drinking is associated with greater frequency of sexual intercourse and greater number of past sexual partners (Graves and Leigh, 1995; Shillington et al., 1995), including more casual sexual partners (Graves, 1995; Michael et al., 1994), which also increase risk for STI following from unprotected sexual intercourse (Ericksen and Trocki, 1994). However, alcohol-related reproductive dysfunctions have been reported in both animal and human studies (Emanuele and Emanuele, 2001; Emanuele et al., 2003), suggesting likelihood of pregnancy and subsequent childbearing may decrease with continued use and misuse of alcohol. In women, even moderate alcohol consumption is associated with menstrual, gynecological, and obstetric problems that include infertility and spontaneous abortion or miscarriage (Abel, 1997; Hakim et al., 1998; Jensen et al., 1998; Kesmodel et al., 2002; Mendelson and Mello, 1998; Ryback, 1977; Wilsnack et al., 1984). Alcohol effects are also observed in men, with heavy or chronic consumption associated with lower sperm count and impotence (O’Farrell et al., 1998; Wright et al., 1991). 
To date, alcohol associations with timing of first childbirth have yet to be examined across both early and later stages of reproductive development. Although early alcohol use is a strong predictor of future alcohol problems, including alcohol use disorders (Grant and Dawson, 1997), review of reproductive correlates of early alcohol use and continued use and misuse offers no clear prediction regarding overall associations with early versus later childbearing. In this study, we use survival analytic techniques to examine the historical relationship between reproductive onset and alcohol use disorder, specifically, lifetime history of alcohol dependence (AD), in older and young adult cohorts of Australian twins, together spanning ages 22 to 93 .

While research on early childbearing has largely focused on women, we include men as well as women by examining age at first childbirth rather than age at first pregnancy. To ensure specificity of observed $\mathrm{AD}$ effects, we select as control variables a host of well-documented correlates of AD and reproductive timing, including sociodemographic characteristics, history of psychopathology, and family and childhood risks. History of regular smoking is also included as regular smoking increases risk for AD (Grucza and Beirut, 2006; Madden et al., 2000) and smoking has been linked with infertility and spontaneous abortion in women who smoke (Augood et al., 1998; DHHS, 2004) and with lower sperm count and motility in men (Vine, 1996). Smoking is also associated with poor overall physical health (DHHS, 2004).

Elective abortion is examined in subsidiary analyses. Results from a handful of studies suggest alcohol and other substance use, including smoking, are more common among women who abort versus carry pregnancies to term (Coleman, 2005), thus abortion could explain at least in part observed associations between reproductive timing and AD. Furthermore, evidence of heritable variation in AD is now considerable (e.g., Heath et al., 1997; Kendler et al., 1994; McGue, 1994; Prescott and Kendler, 1999), with heritable variation in age at first reproduction also reported (Kirk et al., 2001; Neiss et al., 2002). As part of subsidiary analyses, genetic sources of covariation are examined.

\section{MATERIALS AND METHODS}

\section{Participants}

Respondents were drawn from two broadly representative Australian volunteer twin panels maintained by the Australian National Health and Medical Research Council (NHMRC). Reflecting the predominantly Caucasian Australian population from which an older and young twin cohort were ascertained, respondents are of primarily European decent. While well-educated individuals are over-represented, this bias is more pronounced in the older cohort ascertained as adults than in the younger cohort, who were recruited as children and volunteered by their parents. However, any impact of differential participation rates as a function of educational attainment in the older cohort appears minimal (Heath et al., 1997, 2001a), as does potential bias with respect to drinking behavior (Jardine and Martin, 1984).

Cohort I. The older cohort, Cohort I, were recruited as adults and first surveyed by mailed questionnaire over the period 1980 to
1981 (Heath et al., 1997). During 1980 to 81, 5,967 adult twin pairs born between 1893 and 1964 were contacted and asked to complete a brief self-report questionnaire. Questionnaires were returned by 8196 individual twins (68\% individual response rate), including 3,810 pairs (64\% pair-wise response rate). During 1988 to 1989, pairs for whom both twins returned the 1980 to 1981 questionnaire were asked to complete a follow-up questionnaire. The follow-up questionnaire replicated most of the original items, with additional assessment of female reproductive health. Follow-up questionnaire data were obtained from both members of 6234 individual twins, including 2995 pairs $(82 \%$ individual and $79 \%$ pair-wise response rates). In 1992, all twins from the 1988 to 1989 sample were asked to complete a structured diagnostic interview. 206 twin pairs from an earlier laboratory study (Martin et al., 1985a,b) were also invited to participate. In all, 5963 individual twins age 27 to 90 were interviewed, including 2722 pairs (89\% individual and $85 \%$ pair-wise response rates).

Twins were selected from Cohort I if they had data on lifetime DSM-III-R AD symptoms assessed during interview and variables used to code reproductive onset, which were included in the 1988 to 1989 questionnaire, but omitted from interview. Of 5879 twins completing 1988 to 1989 questionnaire and interview assessments, 5514 $(94 \%)$ had data on both AD and reproductive onset, including 3634 female and 1880 male respondents. Age at interview of selected twins ranged from 28 to 93 [M (SD) $=44.68(12.37)]$.

Cohort II. Cohort II twins were born between 1964 and 1971 and ascertained as children by their parents in response to flyers distributed throughout Australian schools during 1980 to 1982 (Heath et al., 2001a). During the period 1990 to 92, 8536 twins were contacted and asked to complete a brief self-report questionnaire of similar format and item content to the 1988 to 1989 questionnaire administered to Cohort I twins. Questionnaires were returned by 5058 individual twins ( $59 \%$ individual response rate), including 2270 pairs (53\% pair-wise response rate). Excluding pairs that could not be located or where either twin was deceased or too impaired to give informed consent, 8020 twins (4010 pairs) were re-contacted between 1996 and 2000 for interview assessment. During this period, structured diagnostic interviews were administered to 6257 twins, including 2723 pairs $(78 \%$ individual and $68 \%$ pair-wise response rates).

Twins were selected from Cohort II if they had data on lifetime DSM-IV AD symptoms and variables used to code reproductive onset, both assessed during interview. Of 6257 interviewed twins, $6129(98 \%)$ had data on both AD and reproductive onset, including 3381 female and 2748 male respondents. Age at interview of selected twins ranged from 22 to 36 [M (SD) $=30.42(2.45)]$.

\section{Measures}

Both cohorts completed similar self-report questionnaires and either a long or abbreviated telephone adaptation of the SemiStructured Assessment of the Genetics of Alcoholism (SSAGA; Bucholz et al., 1994; Hesselbrock et al., 1999). The SSAGA was developed for the Collaborative Study on the Genetics of Alcoholism to assess physical, psychological, and social manifestations of alcohol abuse or dependence and related psychiatric disorders in adults and is based on previously validated research interviews (e.g., DIS, CIDI, HELPER, SAM, SADS, and SCID). Trained interviewers, who were supervised by a project coordinator and clinical psychologist, administered all interviews. Interviews were tape-recorded and a random sampling of tapes was reviewed for quality control and coding inconsistencies. Informed consent was obtained from all participants prior to their participation using procedures approved by the institutional review boards at both Washington University School of Medicine and Queensland Institute of Medical Research.

Measures were drawn from interview assessments unless otherwise indicated. A summary of individual measures follows, with 
descriptive statistics presented in Table 1 by cohort and respondent sex. Where available, age of onset is also shown.

Reproductive Onset. For respondents reporting biological children, age at first childbirth was computed by subtracting respondent's date of birth from the date of birth of his or her firstborn child. Respondents in Cohort I were asked to provide dates of birth of biological children only in the 1988 to 1989 questionnaire.

Alcohol Dependence. For Cohort I, lifetime history of AD was coded from DSM-IV AD symptoms based on a DSM-III-R AD assessment. The SSAGA administered to Cohort I predates DSMIV; however, an approximate algorithm for DSM-IV AD without clustering criteria was subsequently applied by Heath and colleagues (see Heath et al., 2001b). Consistent with other reports (Grant et al., 2007; Knopik et al., 2006), respondents in Cohort I were diagnosed with $\mathrm{AD}$ if they endorsed three or more DSM-IV AD symptoms. For Cohort II, DSM-IV AD was directly assessed, with age of onset defined as age at first 12-month clustering of three or more AD symptoms. An equivalent measure of $\mathrm{AD}$ age of onset was not available for Cohort I.

Control Variables. In addition to birth year, coded in 5-year intervals, educational attainment, religiosity, and marital history were included among sociodemographic controls variables. For Cohort I, all but marital status were omitted from interview and thus drawn from the 1988 to 1989 questionnaire. Dummy variables for dropping out of and completing high-school were computed with any tertiary education comprising the reference group. Respondents reporting any versus no religion were coded positive for religious affiliation. Weekly or more church attendance was coded from respondent report of frequency of church attendance using a scale ranging from $1=$ "more than once a week" to 5 = "rarely or never", with $2=$ "once a week." Marital dissolution was not included among control variables because $<10 \%$ of Cohort I reported marital separation or divorce due in part to restrictive Australian divorce laws prior to 1975 . Less than $10 \%$ of Cohort II also reported marital separation or divorce, although they are relatively young, with dissolution more likely as Cohort II age through their 30s and beyond. For both cohorts, history of never versus ever marrying was instead examined.

For Cohort I, history of regular smoking was assessed only in the 1988 to 1989 questionnaire. Respondents who self-described as "ex-" or "current smoker"(s) were coded positive for regular smoking in Cohort I. For Cohort II, regular smoking was coded if respondents reported (1) having smoked 100 or more cigarettes, or (2) smoking $<100$, but more than 20 cigarettes, and having smoked at least 1 or 2 days per week for a period of three weeks or more. For Cohort II, age of onset of regular smoking was defined as age first smoked at least 1 or 2 days per week for a period of 3 weeks or more. Age of onset of regular smoking was not assessed in Cohort I.

Childhood conduct disorder (CD), lifetime history of major depressive disorder (MDD), and suicide attempt and panic attack histories were included among psychiatric control variables, each assessed as part of the SSAGA. For both cohorts, relaxed criteria were used to diagnose CD, defined as three or more DSM-IV CD symptoms each with onset before age 18 . Likewise, the broader construct of panic attack, rather than panic disorder, was used. For Cohort I, as with AD, DSM-IV criteria were applied to DSM-III-R assessment of MDD and panic attack. For Cohort II, DSM-IV MDD and panic attack were directly assessed. Age of onset of MDD was defined as age at first clustering of five or more DSM-IV major

Table 1. Descriptive Statistics by Cohort and Sex

\begin{tabular}{|c|c|c|c|c|}
\hline & \multicolumn{2}{|c|}{ Cohort I } & \multicolumn{2}{|c|}{ Cohort II } \\
\hline & Women $(n=3634)$ & Men $(n=1880)$ & Women $(n=3281)$ & Men $(n=2723)$ \\
\hline Biological children, $n(\%)$ & $2797(77)$ & $1264(67)$ & $1599(47)$ & $1030(37)$ \\
\hline Age at first childbirth, M (SD) & $25.85(4.05)$ & $27.49(4.29)$ & $25.17(3.76)$ & 26.15 (3.33) \\
\hline $\mathrm{AD}, n(\%)$ & $154(4)$ & $328(17)$ & $522(15)$ & $842(31)$ \\
\hline Age of onset, M (SD) & - & - & $21.74(3.80)$ & $21.32(3.59)$ \\
\hline \multicolumn{5}{|l|}{ Sociodemographic characteristics } \\
\hline \multicolumn{5}{|l|}{ Educational attainment } \\
\hline High school drop-out, $n(\%)$ & $1271(35)$ & $320(17)$ & $347(10)$ & $254(9)$ \\
\hline High school degree, $n(\%)$ & $1324(37)$ & 719 (39) & $1836(54)$ & $1569(57)$ \\
\hline \multicolumn{5}{|l|}{ Religiosity } \\
\hline Religious affiliation, $n(\%)$ & $2979(82)$ & $1401(75)$ & $2452(73)$ & $1775(65)$ \\
\hline Weekly church attendance, $n(\%)$ & $863(24)$ & $375(20)$ & $375(11)$ & $213(8)$ \\
\hline \multicolumn{5}{|l|}{ Marital status } \\
\hline Never married, $n(\%)$ & $394(11)$ & $279(15)$ & $1311(39)$ & $1329(48)$ \\
\hline \multicolumn{5}{|l|}{ Smoking history } \\
\hline Regular smoking, $n(\%)$ & $1488(41)$ & $928(49)$ & $1640(49)$ & $1447(53)$ \\
\hline Age of onset, M (SD) & - & - & $16.48(2.77)$ & $16.37(3.11)$ \\
\hline \multicolumn{5}{|l|}{ History of psychopathology } \\
\hline $\mathrm{CD}, n(\%)$ & $86(2)$ & $308(16)$ & $261(8)$ & $548(20)$ \\
\hline MDD, $n(\%)$ & 792 (22) & $299(16)$ & $1130(34)$ & 627 (23) \\
\hline Age of onset, M (SD) & - & - & $22.48(5.52)$ & $22.41(5.43)$ \\
\hline Suicide attempt, $n(\%)$ & $110(3)$ & $39(2)$ & $161(5)$ & $90(3)$ \\
\hline Age of onset, M (SD) & - & - & $18.80(4.86)$ & $20.51(5.52)$ \\
\hline Panic attack, $n(\%)$ & $144(4)$ & $43(2)$ & $350(10)$ & $153(6)$ \\
\hline Age of onset, M (SD) & - & - & $19.54(6.89)$ & $18.02(7.05)$ \\
\hline \multicolumn{5}{|l|}{ Family and childhood risks } \\
\hline Maternal alcoholism, $n(\%)$ & $135(4)$ & $54(3)$ & $127(4)$ & 77 (3) \\
\hline Paternal alcoholism, $n(\%)$ & $603(17)$ & $309(16)$ & 651 (19) & 468 (17) \\
\hline CSA, $n(\%)$ & $205(6)$ & $48(3)$ & $573(17)$ & $155(6)$ \\
\hline Age of onset, M (SD) & - & - & $10.68(4.28)$ & $10.81(3.40)$ \\
\hline
\end{tabular}

$A D$, alcohol dependence; $C D$, childhood conduct disorder; MDD, major depressive disorder; CSA, childhood sexual abuse. 
depressive symptoms in an episode of at least 2 weeks duration. For panic attack, age of onset was defined as age at first discrete period of unexpected intense fear or discomfort, in which respondents experienced three or more DSM-IV panic attack symptoms. Equivalent measures of age of onset of MDD and panic attack were not available for Cohort I. For both cohorts, history of suicide attempt was assessed, but only in Cohort II was age of onset available.

Maternal and paternal alcohol problems were coded from respondent report of biological parent history of alcohol-related problems with health, family, job, or police, or other problems. Childhood sexual abuse (CSA) was defined as unwanted or forced sexual activity prior to age 18. Age of onset of CSA was assessed in Cohort II only.

Abortion History. For both cohorts, abortion history was included among questionnaire assessments of female reproductive heath, with male respondents instructed to skip this section. Respondents reporting a past abortion were coded positive for abortion history. Age of first or subsequent abortions was not assessed in either cohort.

Zygosity. Zygosity was diagnosed based on twins' responses to standard questions regarding similarity and the degree to which others confused them (Nichols and Bilbro, 1966).

\section{Analytic Strategy}

The present study analyzes data from individual twins to examine phenotypic associations between reproductive timing and $\mathrm{AD}$, and in subsidiary analyses, pair-level data to examine heritable sources of covariation. Because not all respondents, particularly those in the young cohort, had aged through periods of highest likelihood of childbearing, time-to-event data were analyzed using survival analysis. Associations between $\mathrm{AD}$ and reproductive onset were examined separately for women and men within cohort given (1) both cohort and sex differences in the prevalence of $\mathrm{AD}$, and (2) cohort differences in the assessment of $\mathrm{AD}$, including availability of age of onset measures.

We tested for zygosity differences that might identify limitations to the generalizability of twin data as part of preliminary analyses. Because monozygotic (MZ) twinning occurs at random, MZ twins will represent a near-random sample of genotypes in the general population. In contrast, dizygotic (DZ) twining shows weak associations with factors including maternal age and socioeconomic status (Bulmer, 1970). In preliminary analyses of reproductive and AD onset, cumulative failure curves were estimated using the KaplanMeier survivor function (Kaplan and Meier, 1958), with log-rank tests to identify significant differences in equality of survivor functions by gender and cohort.

To examine reproductive onset as a function of $\mathrm{AD}$ history, without and with adjustment for control variables, Cox proportional hazards regression (Cox, 1972) was used. For both cohorts, AD was modeled as a time-invariant predictor of reproductive onset, as were all control variables. AD and relevant control variables (MDD, suicide attempt, panic attack, and CSA), were also examined as timevarying predictors in the young cohort to ensure onset before or at the same time of first reproduction. In these analyses, the Efron approximation (Efron, 1977) was used for survival ties. For Cohort I, examination of AD, MDD, suicide attempt, panic attack, and CSA as time-varying predictors of reproductive onset was not possible because age of onset was not available for these measures.

In subsidiary analyses, the effect of abortion history on reproductive timing was examined using data from a subsample of female respondents with non-missing questionnaire data $\left(\mathrm{n}_{\text {Cohort I }}=3576\right.$, $\mathrm{n}_{\text {Cohort II }}=1009$ ). For each cohort, log-rank tests were used to identify significant differences in equality of survivor functions by abortion history. Subsidiary analyses of genetic influences contributing to observed associations between reproductive timing and $\mathrm{AD}$ were conducted using data from complete pairs of MZ and DZ twins
(Cohort I: $n_{\text {female MZ }}=858, n_{\text {male } \mathrm{MZ}}=363, n_{\text {female } \mathrm{DZ}}=476, n_{\text {male }}$ $\mathrm{DZ}=194, n_{\text {opposite-sex DZ }}=519$; Cohort II: $n_{\text {female MZ }}=676, n_{\text {male }}$ $\left.\mathrm{MZ}=475, n_{\text {female } \mathrm{DZ}}=491, n_{\text {male } \mathrm{DZ}}=376, n_{\text {opposite-sex DZ }}=635\right)$. The following variables were modeled as time-invariant predictors of reproductive onset in genetically-informed Cox analyses: AD, zygosity, cotwin $\mathrm{AD}$, the interaction between zygosity and cotwin AD (a test of genetic effects), cotwin sex, and the interaction of zygosity, cotwin $\mathrm{AD}$, and cotwin sex (a test of sex differences in genetic effects).

All survival analyses were conducted using STATA version 8.2 (StataCorp, 2005), with the Huber-White robust variance estimator to compute standard errors and confidence intervals adjusted for nonindependence (i.e., the correlated nature) of data on twin pairs. To examine potential violation of the proportional hazards assumption, such as might be the case if $\mathrm{AD}$ effects on reproductive onset differ for earlier versus later age periods, the Grambsch and Therneau test of Schoenfeld residuals (Grambsch and Therneau, 1994) was employed. Where appropriate, age-interactions were computed and modeled to correct proportional hazards violations (Cleves et al., 2004).

\section{RESULTS}

\section{Preliminary Analyses}

In both cohorts, more women than men reported biological children [Cohort I: $\chi^{2}(\mathrm{df})=60.49$ (1), $p<0.0001$; Cohort II: $\left.\chi^{2}(\mathrm{df})=59.58(1), p<0.0001\right]$. Results of log-rank tests indicate significant gender and cohort differences in the cumulative probability of first childbirth. Within cohort, women reproduced earlier on average than men [Cohort I: $\chi^{2}$ $(\mathrm{df})=175.44 \quad$ (1), $p<0.0001 ;$ Cohort $\quad$ II: $\chi^{2}$ (df) $=73.71$ (1), $p<0.0001]$, with men and especially women in the older cohort reproducing earlier than men and women in the younger cohort [women: $\chi^{2}(\mathrm{df})=488.08$ (1), $p<0.0001$; men: $\chi^{2}(\mathrm{df})=142.80$ (1), $\left.p<0.0001\right]$. Consistent with previous reports, rates of AD are higher for men than women [Cohort I: $\chi^{2}(\mathrm{df})=271.00$ (1), $p<0.0001$; Cohort II: $\left.\chi^{2}(\mathrm{df})=202.46(1), p<0.0001\right]$ and in Cohort II, onset of AD occurred earlier on average for men $\left[\chi^{2}\right.$ $(\mathrm{df})=204.63$ (1), $p<0.0001]$.

Alcohol dependence history is negatively associated with reproduction among women, in particular. In Cohort I, 64\% $(n=98)$ of alcoholic (AD +$)$ women reported biological children, compared with 78\% $(n=2699)$ of non-alcoholic (AD-) women $\left[\chi^{2}(\mathrm{df})=16.12(1), p<0.0001\right]$. Fifty-nine percent $(n=195)$ of $\mathrm{AD}+$ men compared with $69 \%(n=1069)$ of AD- men reported biological children $\left[\chi^{2}(\mathrm{df})=10.92(1)\right.$, $p<0.001]$. In Cohort II, 38\% $(n=196)$ of AD + women reported biological children, compared with $49 \%(n=1403)$ of $\mathrm{AD}-$ women $\left[\chi^{2}(\mathrm{df})=23.52(1), p<0.0001\right]$. A roughly equivalent proportion of $\mathrm{AD}+$ and $\mathrm{AD}-$ men reported biological children in Cohort II $-36 \%(n=300)$ of AD + men and $38 \% \quad(n=730)$ of $\mathrm{AD}-\operatorname{men}\left[\chi^{2}(\mathrm{df})=1.78 \quad(1)\right.$, $p=0.18]$.

Tests for zygosity differences in AD and age at first childbirth largely support generalizability of twin data. Zygosity is unrelated to AD in Cohort I [women: $\chi^{2}(\mathrm{df})=2.63$ (1), $p=0.10$; men: $\left.\chi^{2}(\mathrm{df})=3.52(1), p=0.06\right]$ and for women in Cohort II [women: $\chi^{2}(\mathrm{df})=3.24(1), p=0.07$ ]. There is 
a slight difference by zygosity for men in Cohort II $\left[\chi^{2}\right.$ $(\mathrm{df})=4.04$ (1), $p=0.04]$. For both sexes, differences by zygosity in the cumulative probability of first childbirth are nonsignificant in Cohort I [women: $\chi^{2}(\mathrm{df})=0.07$ (1), $p=0.79$; men: $\left.\chi^{2}(\mathrm{df})=0.03(1), p=0.86\right]$ and Cohort II [women: $\chi^{2}(\mathrm{df})=0.03(1), p=0.86$; men: $\chi^{2}(\mathrm{df})=0$ (1), $p=1.00]$.

\section{Cox Analyses of Reproductive Timing and $A D$}

For models of $\mathrm{AD}$ specified as a time-invariant predictor of reproductive onset, unadjusted and adjusted HRs and 95\% Confidence Intervals (CIs) are shown in Tables 2 and 3 for Cohort I and Cohort II, respectively. Results of AD modeled as a time-varying predictor of reproductive onset in Cohort II, along with time-varying control variables, are also shown in Table 3.

Models With Time-Invariant Predictors. In Cohort I, history of $\mathrm{AD}$ is associated with delayed reproduction for women after age 29 , with $73 \%$ decreased likelihood of first childbirth. Through age 29, a smaller, but nonsignificant decrease $(19 \%)$ is observed. Similar effects are obtained in adjusted models. For men in Cohort I, history of AD is not significantly associated with delayed reproduction in either adjusted or unadjusted models.

In Cohort II, AD is associated with delayed reproduction in women after age 24 , with $40 \%$ decreased likelihood of first childbirth. AD remains predictive of delayed childbearing in adjusted models, but without significant age interaction. In adjusted models, AD is associated with $28 \%$ decreased likelihood of first childbirth. For men in Cohort II, AD is associated with delayed reproduction after age 24, with 18\% decreased likelihood of first childbirth. In adjusted models, $\mathrm{AD}$ is not significantly associated with delayed reproduction in men.

Models With Time-Varying Predictors. In Cohort II, for both women and men, a similar pattern is found when AD is modeled as a time-varying predictor of reproductive onset. In unadjusted models, onset of AD is associated with delayed reproduction in female twins after age 24 , with $38 \%$ decreased likelihood of first childbirth. AD onset is also associated with delayed reproduction in adjusted models, but with reduced effect and no significant age interaction. In adjusted models, with MDD, suicide attempt, panic attack, and CSA also modeled as time-varying predictors, AD is associated with $23 \%$ decreased likelihood of first childbirth among women.

Table 2. Hazard Ratios (and 95\% Cls) From Cox Proportional Hazards Models: Cohort I

\begin{tabular}{|c|c|c|c|c|}
\hline \multirow[b]{2}{*}{ Predictor (risk period)* } & \multicolumn{2}{|c|}{ Women } & \multicolumn{2}{|c|}{ Men } \\
\hline & Unadjusted & Adjusted & Unadjusted & Adjusted \\
\hline $\begin{array}{l}\mathrm{AD}(<30) \\
\mathrm{AD}(\geq 30)\end{array}$ & $\begin{array}{l}0.81(0.65-1.00) \\
\mathbf{0 . 2 7}(\mathbf{0 . 1 0 - 0 . 7 5 )}\end{array}$ & $\begin{array}{l}0.84(0.65-1.09) \\
0.29(0.11-0.80)\end{array}$ & ] $0.88(0.76-1.03)$ & $0.99(0.84-1.16)$ \\
\hline \multicolumn{5}{|l|}{ Sociodemographic characteristics } \\
\hline Birth year & & $1.00(0.98-1.02)$ & & $0.97(0.94-0.99)$ \\
\hline HS drop-out $(<20)$ & & 7.46 (4.64-11.99) & & $1.75(1.35-2.27)$ \\
\hline HS drop-out (20-24) & & $2.92(2.47-3.45)$ & & $1.75(1.35-2.27)$ \\
\hline HS drop-out $(\geq 25)$ & & $1.26(1.08-1.46)$ & & $1.13(0.94-1.37)$ \\
\hline HS degree $(<20)$ & & $0.41(0.32-0.54)$ & & \\
\hline HS degree (20-24) & & $0.64(0.56-0.72)$ & & $0.92(0.77-1.09)$ \\
\hline HS degree $(\geq 25)$ & & $0.82(0.71-0.95)$ & & \\
\hline Religious affiliation & & $1.23(1.07-1.41)$ & & $1.23(1.04-1.46)$ \\
\hline Church attendance & & $0.98(0.89-1.07)$ & & $0.90(0.78-1.05)$ \\
\hline Never married $(<25)$ & & ] $004(003-006)$ & & $0.09(0.04-0.21)$ \\
\hline Never married $(\geq 25)$ & & ]$^{0.04}(0.03-0.06)$ & & $0.01(0.002-0.04)$ \\
\hline \multicolumn{5}{|l|}{ Smoking history } \\
\hline Regular smoking $(<20)$ & & $1.64(1.30-2.07)$ & & $1.05(0.92-1.20)$ \\
\hline Regular smoking (20-29) & & ]$_{0.90}(0.82-0.98)$ & & $1.00(0.92-1.20)$ \\
\hline Regular smoking $(\geq 30)$ & & $0.90(0.02-0.90)$ & & $0.78(0.61-1.00)$ \\
\hline \multicolumn{5}{|l|}{ History of psychopathology } \\
\hline CD $(<25)$ & & $1.39(0.98-1.97)$ & & $I_{105}(090-120)$ \\
\hline $\mathrm{CD}(\geq 25)$ & & $0.68(0.39-1.18)$ & & $1.05(0.90-1.22)$ \\
\hline $\operatorname{MDD}(<30)$ & & $11.13(1.03-1.24)$ & & $1.14(0.96-1.36)$ \\
\hline $\operatorname{MDD}(\geq 30)$ & & & & $0.59(0.38-0.91)$ \\
\hline Suicide attempt $(<20)$ & & & & $8.74(2.69-28.40)$ \\
\hline Suicide attempt $(\geq 20)$ & & ]$^{0.95(0.76-1.20)}$ & & $1.00(0.54-1.86)$ \\
\hline Panic attack & & $1.17(0.96-1.41)$ & & $1.12(0.76-1.66)$ \\
\hline \multicolumn{5}{|l|}{ Family and childhood risks } \\
\hline Maternal alcoholism & & $0.82(0.64-1.04)$ & & $1.41(1.03-1.91)$ \\
\hline Paternal alcoholism & & $1.03(0.93-1.14)$ & & $1.11(0.94-1.32)$ \\
\hline CSA & & $1.18(0.99-1.41)$ & & $0.80(0.55-1.56)$ \\
\hline
\end{tabular}

$A D$, alcohol dependence; HS, high school; $C D$, childhood conduct disorder; MDD, major depressive disorder; CSA, childhood sexual abuse. ${ }^{*}$ Risk period in years of age. 


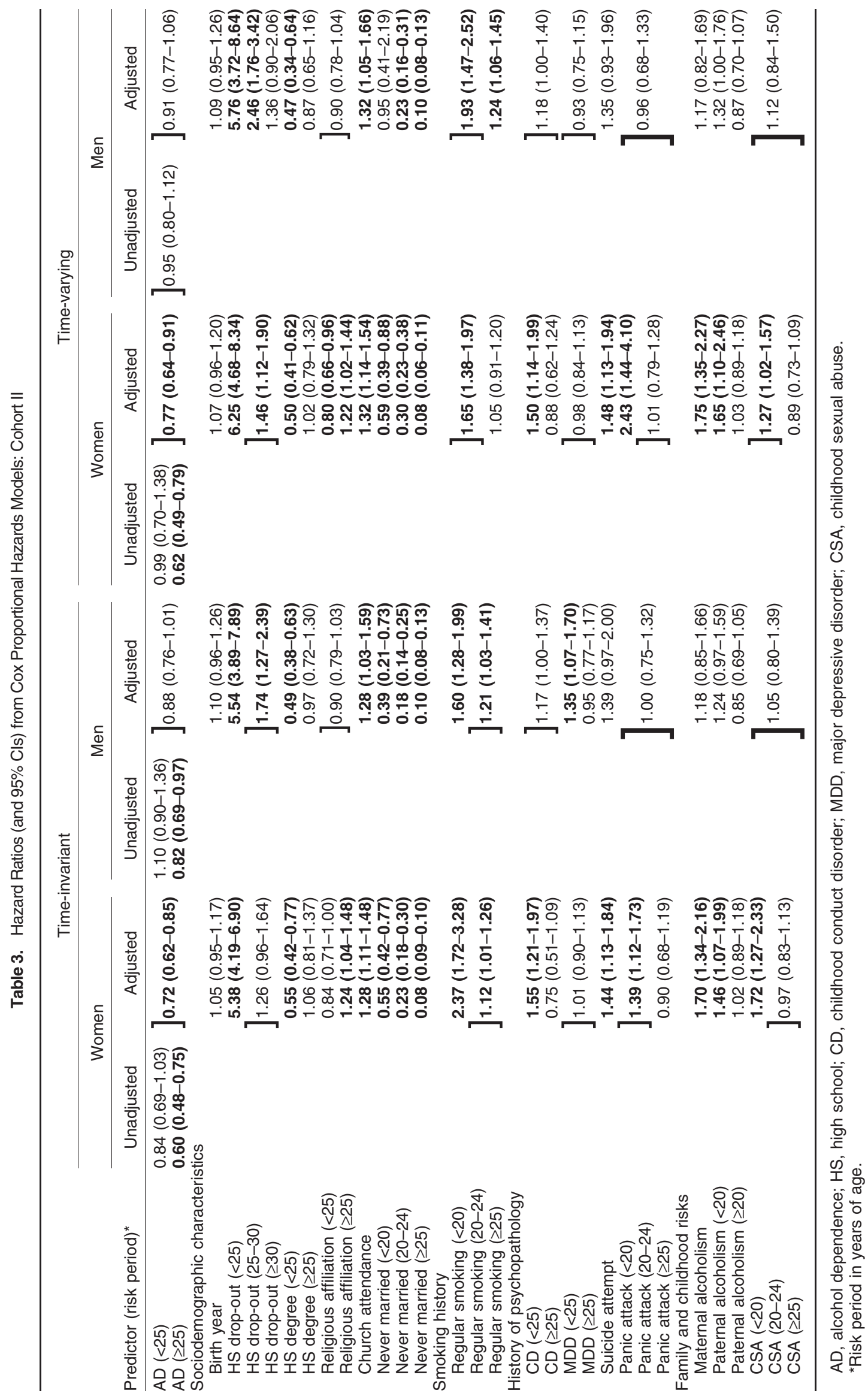


For male twins, onset of AD shows no significant association with age at first reproduction in either unadjusted or adjusted models.

\section{Subsidiary Analyses}

For women in both cohorts, history of abortion is strongly associated with $\mathrm{AD}$ [Cohort I: Odds Ratio $(\mathrm{OR})=3.94$, 95\% CI: 2.72-5.72; Cohort II: OR $=3.16,95 \%$ CI: 2.18 4.59]. However, abortion is not a significant predictor of reproductive timing [Cohort I: $\chi^{2}(\mathrm{df})=3.95(1), p=0.05$; Cohort II: $\left.\chi^{2}(\mathrm{df})=0.46(1), p=0.50\right]$.

Models including variables coding for genetic effects suggest heritable covariation contributes little to observed associations between reproductive timing and AD. For women in Cohort I, the interaction between zygosity and co-twin AD is nonsignificant $(\mathrm{HR}=1.35,95 \%$ CI: $0.51-3.62)$, as is the interaction of zygosity, cotwin $\mathrm{AD}$, and cotwin sex $(\mathrm{HR}=1.45,95 \%$ CI: 0.62-3.39). In Cohort II, where significant associations between reproductive timing and AD are observed for both sexes (for men, in adjusted models only), the interaction between zygosity and co-twin $\mathrm{AD}$ is nonsignificant for both women (HR $=0.84,95 \%$ CI: $0.41-1.70)$ and men $(\mathrm{HR}=1.09,95 \%$ CI: 0.29-4.08). Nonsignificant interactions of zygosity, cotwin $\mathrm{AD}$ and cotwin sex are also observed for women (HR $=0.97,95 \%$ CI: $0.49-1.93)$ and men $(\mathrm{HR}=1.26,95 \%$ CI: 0.52-3.04) in Cohort II.

\section{DISCUSSION}

To date, reproductive correlates of alcohol use and misuse have been reported in two relatively distinct literatures - research linking adolescent drinking with risky sexual behavior predictive of early childbearing, and studies of reproductive dysfunctions in adult drinkers suggestive of delayed childbearing. The present study is the first to report on the relationship between lifetime history of alcohol dependence $(\mathrm{AD})$ and reproductive onset examined across reproductive development.

In both older and young cohorts, a consistent pattern of overall delayed reproduction was observed for alcoholic compared with non-alcoholic women, with little effect of AD on reproductive timing in men. In the older cohort, born between 1893 and 1964, history of AD was associated with delayed reproduction in women, but particularly after age 29 . In the young cohort, born between 1964 and 1971, AD was associated with delayed reproduction after age 24 in both women and men. Adjusting for sociodemographic characteristics, regular smoking, history of psychopathology, and family and childhood risks, AD was predictive of delayed childbearing in women, but without age interaction in the young cohort. A similar pattern of delayed reproduction was observed with $\mathrm{AD}$ and other relevant control variables treated as timevarying predictors in the young cohort. Although early alcohol use and misuse increase risk for high risk sexual behavior associated with very early a childbearing, no evidence for age interactions specific to adolescence was evident.

The effects of $\mathrm{AD}$ on likelihood of first childbirth were stronger for women than men in both cohorts. Findings that alcoholic women may be at heightened risk for delayed reproduction are consistent with research documenting reproductive dysfunctions for women at lower levels of alcohol consumption, compared with men. Evidence of gender differences in physiological vulnerability to alcohol effects also support increased risk for women. Although men drink more frequently than women and consume more alcohol on average (Fillmore et al., 1997; Wilsnack et al., 2000), drink for drink, women absorb more alcohol into their system and with higher blood alcohol levels, the intoxicating effects of alcohol occur more quickly and last longer (CDC, 2006; NIAAA, 1999).

The marked delay in reproductive onset observed in older alcoholic women may be related to the relative rarity of AD in older women, with AD representing a more severe phenotype than for younger women. Only four percent of women in Cohort I met criteria for AD, compared with $17 \%$ of men. In recent cohorts, lifetime prevalence of alcohol use disorders has increased, with larger increases observed for women than men (Grant, 1997; Hasin et al., 2007). Consistent with this trend, we observed $15 \%$ of women and $31 \%$ of men having met criteria for AD in Cohort II.

However, some caution is necessary when interpreting results for the older cohort, where we do not have data on $\mathrm{AD}$ age of onset and thus direction of influence is unknown. If for many women onset of $\mathrm{AD}$ follows rather than precedes first reproduction, estimated effects of AD on timing of first childbirth may be biased. While comparison of models with time-invariant and -varying predictors suggest minimal impact in the young cohort, to the extent that onset of AD occurs earlier for younger women, such comparisons may be less informative.

Including control variables did little to reduce AD effects on reproductive timing for women in either cohort. At the same time, the unique effects of many control variables were quite pronounced, with birth year an important exception. Despite the wide range of ages in the older cohort especially, birth year was not related to reproductive timing for women and only for men in the older cohort was there a weak association with later first childbirth.

For both cohorts, high school drop-out was predictive of earlier first childbirth for women and men, particularly before age 25. In contrast, completing high school was associated with reproductive delay for women in older and young cohorts, the latter before age 25. Similar effects were observed for men in the young cohort. Although early school leavers show increased risk for AD (Crum et al., 1993; Rice et al., 2003), such findings are consistent with research documenting reproductive delays associated with continued education (Heck et al., 1997), and likewise, high rates of high school drop-out among teenage parents (Klepinger et al., 1995; Upchurch and McCarthy, 1990). 
The effects of religiosity on reproductive timing were somewhat mixed, with findings difficult to interpret. Religious affiliation was associated with earlier first childbirth for women and men in the older cohort. However, weekly church attendance was associated with delayed reproduction, although for neither women nor men was the association significant. For women in the young cohort, religious affiliation was also associated with earlier childbearing after age 24 , but delayed childbearing before age 24 . For men, a slight, but nonsignificant delay was observed. In the young cohort, weekly church attendance was associated with earlier first childbirth for both women and men. Not surprisingly, never marrying was strongly predictive of delayed childbearing for men and women in both cohorts.

Although regular smoking and alcohol dependence are highly correlated (Grucza and Beirut, 2006; Madden et al., 2000), history of regular smoking was associated with earlier first childbirth, particularly in the younger cohort. In the older cohort, regular smoking was associated with earlier reproduction, with pronounced effects for women through age 19, and for men, through age 29. A slight albeit significant delay was observed for women in the older cohort, but after age 20. For younger women and men, effects of regular smoking were strongest before age 20 .

For the most part, the effects of co-morbid psychopathology on reproductive timing were also opposite in direction to $\mathrm{AD}$, but consistent with research on psychiatric predictors of teenage childbearing (Kessler et al., 1997). In the young cohort, $\mathrm{CD}$ was associated with earlier childbearing in women through age 24 . For both women and men in the young cohort, $\mathrm{CD}$ was associated with delayed childbearing after age 24, but effects were nonsignificant. In both cohorts, a similar pattern was observed for history of MDD, suicide attempt, and panic attack in models where these variables were examined either as time-invariant or varying predictor of reproductive onset. In the older cohort, MDD predicted earlier childbearing in women, but delayed childbearing in men after age 29. A pronounced effect of suicide attempt was observed in the older cohort for men through age 20. Although each is a well-documented predictor of future $\mathrm{AD}$, family and childhood risk variables showing significant association with reproductive timing also predicted earlier first childbirth.

While effects of $\mathrm{AD}$ on reproductive timing appear robust against a host of correlated sociodemographic, psychiatric, and family and childhood risks, mechanisms underlying observed associations between reproductive onset and AD remain largely unknown. Results are consistent with alcohol- but not smoking-related reproductive dysfunctions, although other unmeasured factors may also contribute to reproductive delay. In addition to biological consequences of drinking, a common inherited liability to later reproduction and AD risk is possible. Although genetic effects were nonsignificant when examined in subsidiary analyses, results for women in the older cohort were of modest magnitude. Given imprecise estimates ( $95 \%$ CIs are wide), genetic sources of co-variation could go undetected in the current sample.

Drinking has been linked with sexual behaviors that often include risky contraceptive practices. With unplanned pregnancy is a leading cause of abortion, elective abortion may also play a role. While we observed risk of AD 3-4 times higher for women who report a previous abortion, associations between reproductive timing and abortion were nonsignificant. Without adequate and updated assessment of abortion and importantly timing of abortion (c.f., Fergusson et al., 2006) in women and in the female partners of men, we are unable to rule out the contribution of abortion to observed associations between $\mathrm{AD}$ and reproductive onset.

Heavy and problem drinkers are at increased risk not only for never marrying, but divorce (Chilcaot and Breslau, 1996; Power et al., 1999; Temple et al., 1991; Yamaguchi and Kandel, 1985), suggesting processes related to maintenance of stable relationships may also contribute to AD associations with reproductive delay. In the present study, prevalence of marital separation or divorce was very low for the older cohort, with restrictive divorce laws prior to 1975 being 1 factor. Prevalence of marital separation or divorce was also low for the young cohort, but may increase in future years as more of these twins marry. The role of marital dissolution in the young cohort will need to be re-visited as follow-up data on this cohort are collected.

Additional considerations limit generalizability of findings. Our sample is predominantly Caucasian and given often substantial race differences in both AD risk (Grant, 1997; Hasin et al., 2007) and timing of first childbearing (Martin et al., 2003), it is possible that patterns of AD-related reproductive delay differ for other populations. Observed patterns might also differ cross-nationally. Athough international comparisons of AD prevalence are difficult because of diagnostic differences and differences in whether prevalence for lifetime versus past year prevalence is reported (WHO, 2004), reproductive onset varies widely even among developed countries, with average age at first childbirth in Australia among the oldest (ABS, 2007).

\section{CONCLUSION}

While adolescent drinking is associated with risky sexual behavior predictive of early childbearing, and early alcohol use is a strong predictor of future alcohol problems, we document AD-related reproductive delay in two cohorts of women. Although animal studies suggest hormonal interactions are important (Emanuele and Emanuele, 2001; Emanuele et al., 2003), underlying mechanisms, biological or otherwise, are not fully understood. In attempt to better understand the nature of $\mathrm{AD}$ differences in reproductive onset, continued research on risks upstream of both $\mathrm{AD}$ and onset of reproduction require further attention. In addition to reproductive dysfunctions associated with alcohol and other substance use, future research will need to include more comprehensive assessment of both biological and psychosocial risks. 


\section{REFERENCES}

Abel EL (1997) Maternal alcohol consumption and spontaneous abortion. Alcohol Alcohol 32:211-219.

ABS (Australian Bureau of Statistics) (2007). Australian Social Trends 2007. Cat. No. 4102.0. ABS, Canberra, Australia.

Augood C, Duckitt K, Templeton A (1998) Smoking and female infertility: a systematic review and meta-analysis. Hum Reprod 13:1532-1539.

Bailey SL, Pollock NK, Martin CS, Lynch KG (1999) Risky sexual behaviors among adolescents with alcohol use disorders. J Adolesc Health 25:179-181.

Bucholz KK, Cadoret R, Cloninger CR, Dinwiddie SH, Hesselbrock VM, Nurnberger JI Jr, Reich T, Schmidt I, Schuckit MA (1994) A new, semistructured psychiatric interview for use in genetic linkage studies: a report on the reliability of the SSAGA. J Stud Alcohol 55:149-158.

Bulmer MG (1970) The Biology of Twinning in man. Clarendon Press, Oxford.

CASA (National Center on Addiction and Substance Abuse at Columbia University) (1999). Dangerous Liaisons: Substance Abuse and sex. National Center on Addiction and Substance Abuse at Columbia University, New York.

CDC (Centers for Disease Control and Prevention) (2006). Excessive Alcoho use and Risks to Women's Health. Centers for Disease Control and Prevention, Atlanta.

Chilcaot HD, Breslau N (1996) Alcohol disorders in young adulthood: effects of transitions into adult roles. J Health Soc Behav 37:339-349.

Cleves M, Gould WW, Gutierrez RG (2004) Introduction to Survival Data Analysis With Stata, revised edition. Stata Press, College Station, TX.

Coleman PK (2005) Induced abortion and increased risk of substance use: A review of the evidence. Current Women's Health Reviews 1:21-34.

Cox DR (1972) Regression models and life tables (with discussion). J Roy Stat Soc, Ser B (Methodological) 34:187-220.

Crum RM, Helzer JE, Anthony JC (1993) Level of education and alcohol abuse and dependence in adulthood: A further inquiry. Am J Public Health 83:830-837.

DHHS (U.S. Department of Health and Human Services) (2004). Health Consequences of Smoking: A Report of the Surgeon General. U.S. Department of Health and Human Services, Office of the Surgeon General, Rockville, MD.

Efron B (1977) The efficiency of Cox's likelihood function for censored data. J Am Stat Assoc 72:557-565.

Emanuele MA, Emanuele NV (2001) Alcohol and the male reproductive system. Alcohol Health Res World 25:282-287.

Emanuele MA, Wezeman F, Emanuele NV (2003) Alcohol's effects on female reproductive function. Alcohol Health Res World 26:274-281.

Ericksen KP, Trocki KF (1994) Sex, alcohol and sexually transmitted diseases: a national survey. Fam Plann Perspect 26:257-263.

Fergusson DM, Horwood LJ, Ridder EM (2006) Abortion in young women and subsequent mental health. J Child Psychol Psychiatry 47:16-24.

Fergusson DM, Lynskey MT (1996) Alcohol misuse and adolescent sexual behaviors and risk taking. Pediatrics 98:91-96.

Fillmore KM, Golding JM, Leino EV, Motoyoshi M, Shoemaker C, Terry H, Ager CA, Ferrer HP (1997). Patterns and trends in women's and men's drinking, in Gender and Alcohol: Individual and Social Perspectives (Wilsnack RW, Wilsnack SC eds), pp. 21-48. Rutgers Center of Alcohol Studies, New Brunswick, NJ.

Fortenberry JD, Costa FM, Jessor R, Donovan JE (1997) Sex under the influence: a diary self-report study of substance use and sexual behavior among adolescent women. Sex Transm Dis 24:313-319.

Grambsch PM, Therneau TM (1994) Proportional hazards tests in diagnostics based on weighted residuals. Biometrika 81:515-526.

Grant BF (1997) Prevalence and correlates of alcohol use and dependence in the United States: Results of the National Longitudinal Alcohol Epidemiologic Survey. J Stud Alcohol 5:464 473.

Grant BF, Dawson DA (1997) Age at onset of alcohol use and its association with DSM-IV alcohol abuse and dependence: Results from the National Longitudinal Alcohol Epidemiologic Survey. J Subst Abuse 9:103-110.
Grant JD, Heath AC, Bucholz KK, Madden PAF, Agrawal A, Statham DJ, Martin NG (2007) Spousal concordance for alcohol dependence: evidence for assortative mating or spousal interaction effects? Alcohol: Clin Exp Res 31:717-728.

Graves KL (1995) Risky sexual behavior and alcohol use among young adults: results from a national survey. Am J Health Promotion 10:212-224.

Graves KL, Leigh BC (1995) The relationship of substance use to sexual activity among young adults in the United States. Fam Plann Perspect 27:17-22.

Grucza RA, Beirut LJ (2006) Co-occurring risk factors for alcohol dependence and habitual smoking: update on findings from the Collaborative Study on the Genetics of Alcoholism. Alcohol Res Health 29:172-177.

Hakim RB, Gray RH, Zacur H (1998) Alcohol and caffeine consumption and decreased fertility. Fertil Steril 70:632-637.

Hasin DS, Stinson FS, Grant BF (2007) Prevalence, correlates, disability and comorbidity of DSM-IV alcohol abuse and dependence in the United States: results from the National Epidemiologic Survey on alcohol and related conditions. Arch Gen Psychiatry 64:830-842.

Heath AC, Bucholz KK, Madden PAF, Dinwiddie SH, Slutske WS, Statham DJ, Dunne MP, Whitfield JB, Martin NG (1997) Genetic and environmental contributions to alcohol dependence risk in a national twin sample: Consistency of findings in men \& women. Psychol Med 27:1381-1396.

Heath AC, Howells W, Kirk KM, Madden PAF, Bucholz KK, Nelson EC, Slutske WS, Statham DJ, Marin NG (2001a) Predictors of non-response to a questionnaire survey of a volunteer twin panel: findings from the Australian 1989 twin cohort. Twin Res 4:73-80.

Heath AC, Whitfield JB, Madden PAF, Bucholz KK, Dinwiddie SH, Slutske WS, Bierut LJ, Martin NG (2001b) Towards a molecular epidemiology of alcohol dependence: analysing the interplay of genetic and environmental risk factors. Br J Psychiatry 178(Suppl 40):33-40.

Heck KE, Schoendorf KC, Ventura SJ, Kiely JL (1997) Delayed childbearing by education level in the United States, 1969-1994. Matern Child Health J 1:81-88.

Hesselbrock M, Easton C, Bucholz KK, Schuckit M, Hesselbrock V (1999) A validity study of the SSAGA - a comparison with the SCAN. Addiction 94:1361-1370.

Hingson RW, Strunin L, Berlin BM, Heeren T (1990) Beliefs about AIDS, use of alcohol and drugs, and unprotected sex among Massachusetts adolescents. Am J Public Health 80:295-299.

Howard DE, Wang MQ (2004) Multiple sexual-partner behavior among sexually active US adolescent girls. Am J Health Behav 28:3-12.

Jardine R, Martin NG (1984) Causes of variation in drinking habits in a large twin sample. Acta Genet Med Gemellolog (Roma) 33:435-450.

Jensen TK, Hjollund NHI, Henriksen TB, Scheike T, Kolstad H, Giwercman A, Ernst E, Bonde JP, Skakkebaek NE (1998) Does moderate alcohol consumption affect fertility? Follow-up study among couples planning first pregnancy Br Med J 317:505-510.

Kaplan EL, Meier P (1958) Nonparametric estimation from incomplete observations. J Am Stat Assoc 53:457-481.

Kendler KS, Neale MC, Heath AC, Kessler RC, Eaves LJ (1994) A twin-family study of alcoholism in women. Am J Psychiatry 151:707-715.

Kesmodel U, Wisborg K, Olsen SF, Henriksen TB, Sechler NJ (2002) Moderate alcohol intake in pregnancy and the risk of spontaneous abortion. Alcohol Alcohol 37:87-92.

Kessler RC, Berglund PA, Foster CL, Saunders WB, Stang PE, Walters EE (1997) Social consequences of psychiatric disorders II: Teenage parenthood. Am J Psychiatry 154:1405-1411.

Kinsman SB, Romer D, Furstenberg FF, Schwarz DF (1998) Early sexual initiation: the role of peer norms. Pediatrics 102:118-1192.

Kirby D (2002) Antecedents of adolescent initiation of sex, contraceptive use and pregnancy. American Journal of Health Behavior 26:473-485.

Kirk KM, Blomberg SP, Duffy DL, Heath AC, Owens IPF, Martin NG (2001) Natural selection and quantitative genetics of life-history traits in Western women: a twin study. Evolution 55:423-435.

Klepinger DH, Lundberg S, Plotnick RD (1995) Adolescent fertility and the educational attainment of young women. Fam Plann Perspect 27:23-28.

Knopik VS, Heath A C, Jacob T, Slutske WS, Bucholz KK, Madden PA, Waldron M, Martin NG (2006) Maternal alcohol use disorder and offspring 
ADHD: disentangling genetic and environmental effects using a childrenof-twins design. Psychol Med 36(10):1461-1471.

Kowaleski-Jones L, Mott FL (1998) Sex, contraception and childbearing among high-risk youth: do different factors influence males and females? Fam Plann Perspect 30:163-169.

Lammers C, Ireland M, Resnick M, Blum R (2000) Influences on adolescents' decision to postpone onset of sexual intercourse: a survival analysis of virginity among youths aged 13 to 18 years. J Adolesc Health 26:42-48.

Lowry R, Holtzman D, Truman BI, Kann L, Collins JL, Kolbe LJ (1994) Substance use and HIV-related sexual behaviors among U.S. high school students: are they related? Am J Public Health 84:1116-1120.

Madden PAF, Bucholz KK, Martin NG, Heath AC (2000) Smoking and the genetic contribution to alcohol-dependence risk. Alcohol Res Health 24:209-214.

Manlove J, Terry E, Gitelson L, Papillo AR, Russell S (2000) Explaining demographic trends in teenage fertility, 1980-1995. Fam Plann Perspect 32:166-175.

Martin JA, Hamilton BE, Sutton PD, Ventura SJ, Menacker F, Munson ML (2003). Births: Final Data for 2002. National Vital Statistics Reports, 52(10). National Center for Health Statistics, Hyattsville Maryland.

Martin NG, Oakeshott JB, Gibson JB, Starmer GA, Perl J, Wilks AV (1985a) A twin study of psychomotor and physiological responses to an acute dose of alcohol. Behav Genet 15:305-347.

Martin NG, Perl J, Oakeshott JB, Gibson JB, Starmer GA, Wilks AV (1985b) A twin study of ethanol metabolism. Behav Genet 15:93-109.

McGue M (1994). Genes, environment and the etiology of alcoholism, in The Development of Alcohol Problems: Exploring the Biopsychosocial Matrix of Risk (Zucker R, Boyd G, Howard J eds), pp. 1-40. U.S. Department of Health and Human Services, Rockville MD.

Mendelson JH, Mello NK (1998) Chronic alcohol effects on anterior pituitary and ovarian hormones in healthy women. J Pharmacol Exp Ther 245:407412.

Michael R, Gagnon J, Lauman E, Kolata G (1994) Sex in America: A Definitive Survey. Little Brown and Company, Boston.

Mott FL, Haurin RJ (1988) Linkages between sexual activity and alcohol and drug use among American adolescents. Fam Plann Perspect 20:15-30.

Neiss M, Rowe DC, Rodgers JL (2002) Does education mediate the relationship between IQ and age of first birth? A behavioural genetic analysis J Biosoc Sci 34:259-275.

NIAAA (National Institute on Alcohol Abuse and Awareness) (1999). Are Women More Vulnerable to Alcohol's Effects?, Alcohol Alert, 46. National Institute on Alcohol Abuse and Awareness, Washington, DC.

Nichols RC, Bilbro WC (1966) The diagnosis of twin zygosity. Acta Genet Statist Med 16:265-275.

O'Farrell TJ, Kleinke CL, Cutter HSG (1998) Sexual adjustment of male alcoholics: changes from before to after receiving alcoholism counseling with and without marital therapy. Addict Behav 23:419-425.
Poulin C, Graham L (2001) The association between substance use, unplanned sexual inter course and other sexual behaviours among adolescent students. Addiction 96:607-621.

Power C, Rodgers B, Hope S (1999) Heavy alcohol consumption and marital status: disentangling the relationship in a national study of young adults. Addiction 94:1477-1487.

Prescott CA, Kendler KS (1999) Genetic and environmental contributions to alcohol abuse and dependence in a population based sample of male twins. Am J Psychiatry 156:34 40.

Rice JP, Neuman RJ, Saccone NL, Corbett J, Rochberg N, Hesselbrock V, Bucholz KK, McGuffin P, Reich T (2003) Age and birth cohort effects on rates of alcohol dependence. Alcohol: Clin Exp Res 27:93-99.

Ryback RS (1977) Chronic alcohol consumption and menstruation. J Am Med Assoc 238(20):2143.

Santelli JS, Brener ND, Lowry R, Bhatt A, Zabin LS (1998) Multiple sexual partners among U.S. adolescents and young adults. Fam Plann Perspect 30:271-275.

Shillington AM, Cottler LB, Compton WM, Spitznagel EL (1995) Is there a relationship between "heavy drinking" and HIV high risk sexual behaviors among general population subjects? Int J Addict 30:1453-1478.

Small SA, Luster T (1994) Adolescent sexual activity: an ecological, risk-factor approach. J Marriage Family 56:181-192.

StataCorp (2005). Stata Statistical Software: Release 8.2. StataCorp LP, College Station, TX.

Temple MT, Fillmore KM, Hartka E, Johnstone B, Leino VE, Motoyoshi M (1991) A meta-analysis of change in marital and employment status as predictors of alcohol consumption on a typical occasion. Br J Addict 86:12691281.

Upchurch D, McCarthy J (1990) The timing of a first birth and high school completion. Am Sociol Rev 55:224-234.

Vine MF (1996) Smoking and male reproduction: a review. Int J Androl 19:323-337.

WHO (World Health Organization) (2004) Global Status Report on Alcohol 2004. World Health Organization, Department of Mental Health and Substance Abuse, Geneva, Switzerland.

Wilsnack SC, Klassen AD, Wilsnack RW (1984) Drinking and reproductive dysfunction among women in a 1981 national survey. Alcohol: Clin Exp Res 8:451-458.

Wilsnack RW, Vogeltanz ND, Wilsnack SC, Harris TR (2000) Gender differences in alcohol consumption and adverse drinking consequences: crosscultural patterns Addiction 95:251-265.

Wright HI, Gavaler JS, Van Thiel D (1991) Effects of alcohol on the male reproductive system. Alcohol Health Res World 15:110-114.

Yamaguchi K, Kandel D (1985) On the resolution of role incompatibility: life event history analysis of family roles and marijuana use. Am J Sociol 90:1284-1325. 